\title{
A deliberate path toward diversity, equity, and inclusion within the ASCI
}

\author{
Lorraine B. Ware, ${ }^{1}$ Kathleen L. Collins, ${ }^{2}$ John B. Hawley, ${ }^{3}$ and Rexford S. Ahima ${ }^{4}$ \\ 'President, American Society for Clinical Investigation (ASCI), 2020-2021; Vanderbilt University Medical Center, Nashville, Tennessee, USA. Editor, JCI Insight, 2019-2024; University of Michigan, Ann Arbor, \\ Michigan, USA. ${ }^{3}$ Executive Director, ASCI, Ann Arbor, Michigan, USA. ${ }^{4}$ Editor, Journal of Clinical Investigation, 2018-2022; Johns Hopkins University, Baltimore, Maryland, USA.
}

$T$ hroughout the spring and summer of 2020 , systemic racism and inequality have been brought into sharp focus across the United States. While much of the discussion has centered on cases of police brutality against Black people and other people of color, these events do not occur in a vacuum. Rather, they occur in a continuum of politics, policies, and practices that has served to suppress whole categories of people. The mission of the American Society for Clinical Investigation (ASCI) is to support the scientific efforts, educational needs, and clinical aspirations of physician-scientists to improve the health of all people. Racial injustice and discrimination in any form undermine this mission by negatively affecting safety, freedom, health equity, and opportunity for our patients, trainees, colleagues, and members. With heightened awareness of continuing racial inequity and injustice within our local, regional, and federal institutions and society as a whole, the ASCI is critically evaluating the current status of diversity, inclusion, and equity within our own organization.

\section{A historical perspective}

Like most major medical and scientific organizations, the ASCI has historically been a society of white men. Although the ASCI only began to accrue data on race and ethnicity in 2018, it is estimated that from 1908 to 2019 , only $1.5 \%$ of ASCI inductees were underrepresented minorities and fewer than $10 \%$ were female $(1,2)$. The dearth of ethnic, racial, and gender diversity in ASCI's first century reflects the homogeneity of the physicianscientist community for the majority of the 20th century; although the representation of women in the physician-scien- tist pipeline is slowly improving, minorities remain markedly underrepresented across all levels of this pipeline, and are particularly underrepresented in senior leadership (3). Improving the diversity of the physician-scientist community must be addressed across all levels of academic medicine and will require multifaceted efforts to eliminate both overt and subtle racial and gender bias and to create better access and opportunity.

\section{ASCl initiatives to support diversity}

Several recent ASCI efforts have broadly targeted the physician-scientist pipeline. The Young Physician-Scientist Award (YPSA) program was established in 2013 to recognize the achievements of young physician-scientists and to provide opportunities for networking and mentoring through attendance and presentation at the Joint Meeting. In 2020, this program was augmented with a dedicated career development program around the topic of effective networking. A second initiative to impact the physician-scientist pipeline was the recent redesign of the ASCI Institutional Representative program (4). The redesign focused on defining the role for institutional representatives coupled with better institutional support. Representatives are encouraged to proactively seek and mentor candidates for nomination for both the YPSA and ASCI with an eye toward diversity, including not just racial and gender diversity but also diversity of scientific and medical disciplines. Although both the YPSA and the Institutional Representative program have made a concerted effort to foster racial and gender diversity, the impact of that effort may not be seen for years. It is encourag- ing, however, that in the 3 years since the ASCI started collecting data on race and ethnicity, the percentage of inductees into ASCI who self-identify as underrepresented minorities has increased from $3.8 \%$ to $20.0 \%$. Raising the upper limit of age for nomination to ASCI to 50 beginning with the 2014 nomination cycle may also have had a positive impact on diversity among nominees. Factors that may prolong the time to a successful independent research career include socioeconomic barriers, disabilities, childbirth, and child and elder care responsibilities; these factors may disproportionately affect minority and female physician-scientists.

The creativity and impact of scientific investigation is improved by diversity ( 5 , 6). Attracting a diversity of talented young people to our field will be facilitated by having diverse role models in senior and leadership positions. As such, the ASCI Council is a highly visible symbol of the physician-scientist establishment. Notably, the current 12-member ASCI council includes 8 women. Fifty percent of ASCI presidents in the past decade have been female, including the last 3 in succession, and all 6 of our elected 2020-2021 Councilors are female. However, the representation of minorities remains low, as does the inclusion of fields outside of Internal Medicine. We must actively seek nominees for ASCI Councilor and Officer positions who better represent the ethnic, racial, and scientific diversity of physician-scientists and the patients we serve.

A cornerstone of the ASCI mission is to publish 2 leading scientific journals, the Journal of Clinical Investigation (JCI), established in 1924, and JCI Insight, launched in 2016. Like the ASCI, the editorial leadership of the JCI has historically been dominated by white men. However, this landscape is changing. Rex Ahima, the first editor of the JCI from a historically underrepresented minority, leads a 45 -member 
editorial team that includes 11 women and 6 self-identified underrepresented minorities. Kathleen Collins, the current editor of JCI Insight, is the first female editor of either journal and leads a 20-member editorial team that includes 9 women and 2 self-identified underrepresented minorities. To address issues of systemic bias in author order, the JCI requires transparency and justification for order of author listing when 2 authors share the first author position on a submitted manuscript (7); suggested methods to reduce gender or racial bias include alphabetical ordering or a coin toss. The JCI has also highlighted issues of gender inequities and the challenges that women from underrepresented minorities face in medicine and academic research $(8$, 9). In this issue of the JCI, a series of articles focuses on specific actions to address racial disparities in health care access and biomedical research (10-12).

\section{Expanding efforts to improve diversity and confront bias}

Improved metrics are only one measure of diversity, inclusion, and equity. To truly foster an inclusive ASCI and an equitable and diverse physician-scientist community, efforts are needed not just to diversify our membership and leadership, but to identify and mitigate racism and unconscious bias within our organization. With this goal at the forefront, the ASCI plans to establish a permanent Diversity, Inclusion, and Equity Committee through pro- posed amendment of the ASCI bylaws. This committee will be charged with ensuring that the organization, its programs, and its mentoring mechanisms are free from racial and gender bias and promote and recognize diversity, inclusion, and equity. The committee will also be responsible for overseeing mentoring efforts that are focused on opportunities for underrepresented minorities. Finally, the committee will be tasked with considering how ASCI can better recognize and promote research into health equity and the health disparities that contribute to racial injustice. Highlighting health disparities research and recognizing excellence in physician-scientists who work in this field through election to the YPSA program and the ASCI are important goals for our organization.

As we undertake these steps, we recognize that we do not have all of the answers. We are committed to making progress to address these challenging issues within our own community, and we welcome comments, ideas, and volunteers who would like to contribute to these efforts at staff@the-asci.org. Although bias may be subtle or unconscious, our efforts to eliminate racism and other forms of discrimination must be conscious, transparent, and deliberate.

Address correspondence to: Lorraine B. Ware (lorraine.ware@vumc.org), Kathleen L. Collins (klcollin@umich.edu), John B.
Hawley (staff@the-asci.org), or Rexford S. Ahima (ahima@jhmi.edu).

1. Resar LM, et al. Equity and diversity in academic medicine: a perspective from the JCI editors. J Clin Invest. 2019;129(10):3974-3977.

2. Marr KA. The ownership paradox: nurturing continuity and change for the future ASCI. J Clin Invest. 2019;129(12):5055-5061.

3. Carethers JM. Diversification in the medical sciences fuels growth of physician-scientists. J Clin Invest. 2019;129(12):5051-5054.

4. Marr KA, Rathmell WK, Hawley JB, Guth KD. Empowering ASCI's support of physician-scientists through stronger institutional connections. JClin Invest. 2019;129(4):1516-1518.

5. AlShebli BK, Rahwan T, Woon WL. The preeminence of ethnic diversity in scientific collaboration. Nat Commun. 2018;9(1):5163.

6. Nielsen MW, et al. Opinion: Gender diversity leads to better science. Proc Natl Acad Sci USA. 2017;114(8):1740-1742.

7. Casadevall A, Semenza GL, Jackson S, Tomaselli G, Ahima RS. Reducing bias: accounting for the order of co-first authors. JClin Invest. 2019;129(6):2167-2168.

8. Beeler WH, Cortina LM, Jagsi R. Diving beneath the surface: addressing gender inequities among clinical investigators. J Clin Invest. 2019;129(9):3468-3471.

9. Golden SH. The perils of intersectionality: racial and sexual harassment in medicine. J Clin Invest. 2019;129(9):3465-3467.

10. South EC, Butler PD, Merchant RM. Toward an equitable society: building a culture of antiracism in health care. J Clin Invest. https:/doi. org/10.1172/JCI141675.

11. Roberts BT, Rodgers GP. NIDDK initiatives addressing health disparities in chronic diseases. J Clin Invest. https://doi.org/10.1172/JCI141563.

12. Cooper LA, Crews DC. COVID-19, racism, the pursuit of health care worthy of trust. J Clin Invest. https://doi.org/10.1172/JCI141562. 